\title{
ANATOMIA DO LENHO DE SENEGALIA MARTIUSIANA (STEUD.) SEIGLER \& EBINGER ${ }^{1}$
}

\author{
PAULO FERNANDO DOS SANTOS MACHADO ${ }^{2}$ \\ JOSE NEWTON CARDOSO MARCHIORI ${ }^{3}$ ANELISE MARTA SIEGLOCH ${ }^{4}$
}

\begin{abstract}
RESUMO
O lenho de Senegalia martiusiana (Fabaceae: Mimosoideae) é anatomicamente descrito e ilustrado com fotomicrografias, salientando-se os seguintes caracteres anatômicos em sua estrutura: porosidade semidifusa; poros solitários em sua maioria; elementos vasculares curtos; placas de perfuração simples; pontoações intervasculares pequenas e ornamentadas; parênquima paratraqueal escasso, com 2-5 células por série; raios homogêneos, com 1-2 células de largura; e fibras libriformes septadas. A estrutura corresponde ao descrito para outras espécies do mesmo gênero, bem como para as antigas "acácias" do subgênero Aculeiferum.

Palavras-chave: Acacia adhaerens, Fabaceae, Leguminosae, Mimosa martiusiana, Mimosoideae, Senegalia martiusiana, Anatomia da madeira.
\end{abstract}

\section{ABSTRACT}

[Wood anatomy of Senegalia martiusiana (Steud.) Seigler \& Ebinger].

The wood of Senegalia martiusiana (Fabaceae: Mimosoideae) is anatomically described and illustrated with photomicrographs. In its structure it should be noted the following features: semi-diffuse porous wood; vessels mostly solitary; short vascular elements; simple perforation plates; short and vestured inter-vessel pits; scarce axial parenchyma, with 2-5 cells per axial series; homogeneous rays, with 1-2 cells wide; and libriform septate fibers. The anatomical structure fits the description to other species of the same genus, as well as to other "acácias" from subgenus Aculeiferum.

Key words: Acacia adhaerens, Fabaceae, Leguminosae, Mimosa martiusiana, Mimosoideae, Senegalia martiusiana, Wood anatomy.

\section{INTRODUÇÃO E REVISÃO DE LITERA- TURA}

O Congresso Internacional de Botânica de 2005 endossou a proposta de Orchard \& Maslin (2003), publicada anteriormente, levando à segregação do gênero Acacia Mill. (Fabaceae). Ao

1 Recebido em 10-9-2014 e aceito para publicação em 30-2-2015.

2 Mestrando do Programa de Pós-Graduação em Engenharia Florestal, Universidade Federal de Santa Maria. Santa Maria, RS, Brasil. Bolsista CNPq. barcasole@gmail.com

3 Engenheiro Florestal, Dr. Bolsista de Produtividade em Pesquisa (CNPQ - Brasil). Professor Titular do Departamento de Ciências Florestais, Universidade Federal de Santa Maria. Santa Maria, RS, Brasil.

4 Doutoranda do Programa de Pós-Graduação em Engenharia Florestal. Bolsista CAPES. Universidade Federal de Santa Maria. Santa Maria, RS, Brasil. reservar o nome genérico para o antigo subgênero Phyllodinae, essa alteração radical implicou na transferência da espécie-tipo, que passou de Acacia nilotica (L.) Delile (atual Vachellia nilotica (L.) P.J.H. Hurter \& Mabb.), nativa da África, para a australiana Acacia penninervis Sieber ex DC. As espécies americanas, por consequência, acabaram transferidas, em sua maioria, para os gêneros Vachellia Wight \& Arn. e Senegalia Raf.

O gênero Senegalia, que abrange a maioria das espécies do antigo subgênero Aculeiferum, reúne umas 106 espécies e 35 variedades no continente americano (Rico-Arce, 2007), em sua maioria lianas de florestas tropicais ou secas. Este é o caso, justamente, de Senegalia martiusiana (Steud.) Seigler \& Ebinger, espécie de ampla distribuição na América do Sul, 
desde a Colômbia e Guiana Francesa até a Bolívia, Paraguai e Santa Catarina. A espécie, que tem como basiônimo Mimosa martiusiana Steud., é frequentemente encontrada em espécimes de herbário sob o nome de Acacia adhaerens Mart., binômio ilegítimo, de acordo com Burkart (1979).

Senegalia martiusiana é facilmente reconhecida na natureza pela abundante pubescência amarelada e os acúleos recurvos, esparsos em ramos de $1-3 \mathrm{~cm}$ de diâmetro. As folhas, de até $16 \mathrm{~cm}$ de comprimento e $12-22$ pares de pinas, reúnem 45-67 pares de folíolos lineares (3-4 x $0,5 \mathrm{~mm}$ ) por pina, pubescentes na face inferior e de margem ciliada. As flores dispõem-se em inflorescências capituladas e os frutos, achatados e com $4 \mathrm{~mm}$ de espessura, variam de 9,5$10,5 \mathrm{~cm}$ de comprimento por 1,8-2,7 cm de largura (Rico-Arce, 2007). No Brasil, a espécie é popularmente conhecida como "vamos-junto", "unha-de-gato" ou "garapiá" (Burkart, 1979).

Com relação à anatomia da madeira, a literatura sobre o antigo gênero Acacia Mill. ainda é notavelmente escassa, frente ao grande número de suas espécies. Entre outros caracteres, Cozzo (1951) e Metcalfe \& Chalk (1972) destacam para o mesmo: elementos vasculares curtos; pontoações intervasculares alternas, ornamentadas e de diâmetro pequeno a médio; placas de perfuração simples; parênquima paratraqueal; raios de células procumbentes; fibras libriformes; e ausência de estratificação.

Com relação ao lenho de espécies brasileiras de Senegalia Raf., foram descritas até o presente momento, mas sob o antigo gênero Acacia Mill: Senegalia bonariensis (Marchiori, 1980a, 1990, 1996), Senegalia nitidifolia (Marchiori, 1990, 1991), Senegalia plumosa (Marchiori, 1990), Senegalia recurva (Marchiori, 1982, 1990), Senegalia tucumanensis (Marchiori, 1980a, 1990, 1994), e Senegalia velutina (Marchiori, 1990, 1995); Senegalia visco (Lorentz ex Griseb) Seigler \& Ebinger, nativa do centro-norte da Argentina, Bolívia e Chile, foi recentemente descrita por Pereira et al. (2015).
Em estudo anatômico, com vistas ao reconhecimento de caracteres distintivos para os atuais gêneros Acacia Mill., Senegalia Raf. e Vachellia Wight \& Arn., Marchiori \& Santos (2011) concluíram, com base em 5 espécies nativas, que Senegalia separa-se das espécies investigadas de Acacia e Vachellia pela presença conspícua de septos em fibras. O presente estudo, além da descrição de uma espécie lenhosa anatomicamente desconhecida, visa a analisar Senegalia martiusiana sob enfoque taxonômico, com o objetivo de reafirmar (ou não) a importância do referido caráter para o gênero botânico em questão.

\section{MATERIAL E MÉTODOS}

O material em estudo consiste na amostra $\mathrm{n}^{\circ} 9$ (xiloteca do MBM, Curitiba, leg. Gert Hatschbach $\mathrm{n}^{\circ} 18.593$, sob o nome de Acacia adhaerens), também registrada na Xiloteca da Universidade Federal do Paraná sob no ${ }^{\circ}$ 1.499.

Para a confecção de lâminas histológicas foram extraídos três corpos de prova $(12$ x $3 \mathrm{~cm})$ do material lenhoso, orientados para a obtenção de cortes nos planos transversal, longitudinal radial e longitudinal tangencial. Outra amostra foi também providenciada, com vistas à maceração.

O preparo de lâminas histológicas seguiu a metodologia descrita em Burger \& Richter (1991). A maceração foi realizada com solução de Jeffrey (Freund, 1970). Os cortes anatômicos foram coloridos com Acridina-Vermelha, Crisoidina e Azul-de-Astra (Dujardin, 1964). O macerado, apenas com Safranina 1\%. A montagem de lâminas permanentes foi feita com Entellan.

A descrição anatômica baseou-se nas recomendações do IAWA Committee (Wheeler et al., 1989). No caso da percentagem dos tecidos, foram realizadas 600 determinações ao acaso, com o auxílio de contador de laboratório, conforme proposto por Marchiori (1980b). A abundância de poros foi obtida a partir de um quadrado de área conhecida, superposto a 
fotomicrografias de seções transversais da madeira.

As medições foram realizadas em microscópio Carl Zeiss, no Laboratório de Anatomia da Madeira da Universidade Federal de Santa Maria (UFSM). Nas características quantitativas, os números entre parênteses equivalem aos valores mínimos e máximos observados; o valor que acompanha a média é o desvio padrão. As fotomicrografias foram tomadas em microscópio Olympus CX40, equipado com câmara digital Olympus Camedia c3000, no Laboratório de Anatomia da Madeira do CESNORS UFSM, em Frederico Westphalen, RS.

\section{DESCRIÇÃO ANATÔMICA}

Anéis de crescimento: pouco distintos, delimitados por fina camada de fibras radialmente achatadas e poros de pequenas dimensões no término do anel.

Vasos: numerosos $(21 \pm 4(14-30)$ poros/ $\mathrm{mm}^{2}$ ), ocupando $40 \pm 8,7 \%$ do volume da madeira. Porosidade semi-difusa. Poros solitários (63\%), em múltiplos radiais de 2-5 (28\%), menos comumente múltiplos racemiformes $(9 \%)$; circulares a ovais $(183 \pm 72(60-295) \mu \mathrm{m})$ e de paredes finas a espessas $(7 \pm 1,9(3,8-12,5)$ $\mu \mathrm{m})$ (Figura 1A,B). Elementos vasculares curtos $(341 \pm 70(170-470) \mu \mathrm{m})$, com placas de perfuração simples, oblíquas ou transversais ao vaso; apêndices curtos $(23,6 \pm 17(10-60)$ $\mu \mathrm{m})$, ausentes ou ambas as extremidades. Pontoações intervasculares pequenas $(6,2 \pm$ $0,8(5,2-7,2) \mu \mathrm{m})$, alternas, poligonais, ornamentadas, com abertura em fenda inclusa, frequentemente coalescente (Figura 1F). Pontoações raio-vasculares circulares $(4,8 \pm$ $0,4(4,1-5,2) \mu \mathrm{m})$, alternas e ornamentadas, com abertura em fenda inclusa. Espessamentos espiralados, ausentes. Conteúdos, presentes.

Parênquima axial: representando $13 \pm 3,5 \%$ do volume da madeira; em arranjo paratraqueal escasso. Conteúdo ausente (Figura 1A,B). Séries parenquimáticas de $174 \pm 46(77-253)$ $\mu \mathrm{m}$ de altura, com 3,2 $\pm 1,1(2-5)$ células (Figura $1 \mathrm{~F})$. Cristais romboédricos, em número de 6-33 por série (Figura 1A).

Raios: numerosos $9 \pm 2(6-13)$ raios $/ \mathrm{mm})$, ocupando $13 \pm 3,9 \%$ do volume da madeira; de $19 \pm 5,4(10-38) \mu \mathrm{m}$ de largura e homogêneos, reúnem apenas células procumbentes (Figura 1E,F). Os bisseriados, de $155 \pm 64$ (70 315) $\mu \mathrm{m}$ e 5-24 células de altura. Os unisseriados de $126 \pm 54(30$ - 238) $\mu \mathrm{m}$ e $2-17$ células de altura. Conteúdos e raios fusionados, presentes. Raios agregados, células envolventes, células radiais de paredes disjuntas e células perfuradas, ausentes.

Fibras: libriformes, septadas (1-2 septos) e não septadas, de $968 \pm 217(480-1260) \mu \mathrm{m}$ de comprimento, com $13 \pm 2,7(8,8-18,8) \mu \mathrm{m}$ de largura, e paredes finas a espessas $(3,1 \pm 1(1,9$ $-4,4) \mu \mathrm{m}$ ), ocupando $34 \pm 3,6 \%$ do volume da madeira (Figura 1B). Fibras septadas e gelatinosas, presentes; espessamentos espiralados e traqueídeos radiais, ausentes.

Outros caracteres: variantes cambiais, tubos laticíferos e taniníferos, canais intercelulares, células oleíferas, células mucilaginosas, estratificação, e máculas medulares, ausentes. Cristais, presentes.

\section{ANÁLISE DA ESTRUTURA ANATÔMICA}

As principais características anatômicas observadas no lenho de Senegalia martiusiana têm ampla ocorrência em Mimosaceae, de acordo com Metcalfe \& Chalk (1972), incluindo, entre outros aspectos: elementos vasculares curtos, parênquima paratraqueal, raios homogêneos e fibras libriformes. As fibras septadas, por sua vez, permitem posicionar a espécie no gênero Senegalia Raf., distintamente das demais "acácias" dos gêneros Vachellia Wight \& Arn. e Acacia Mill., de acordo com Marchiori \& Santos (2011). O caráter fibras septadas, em outras palavras, tem reafirmado o seu valor taxonômico em Senegalia Raf., uma vez que permite uma fácil separação desse gênero em relação a Acacia e Vachellia. 

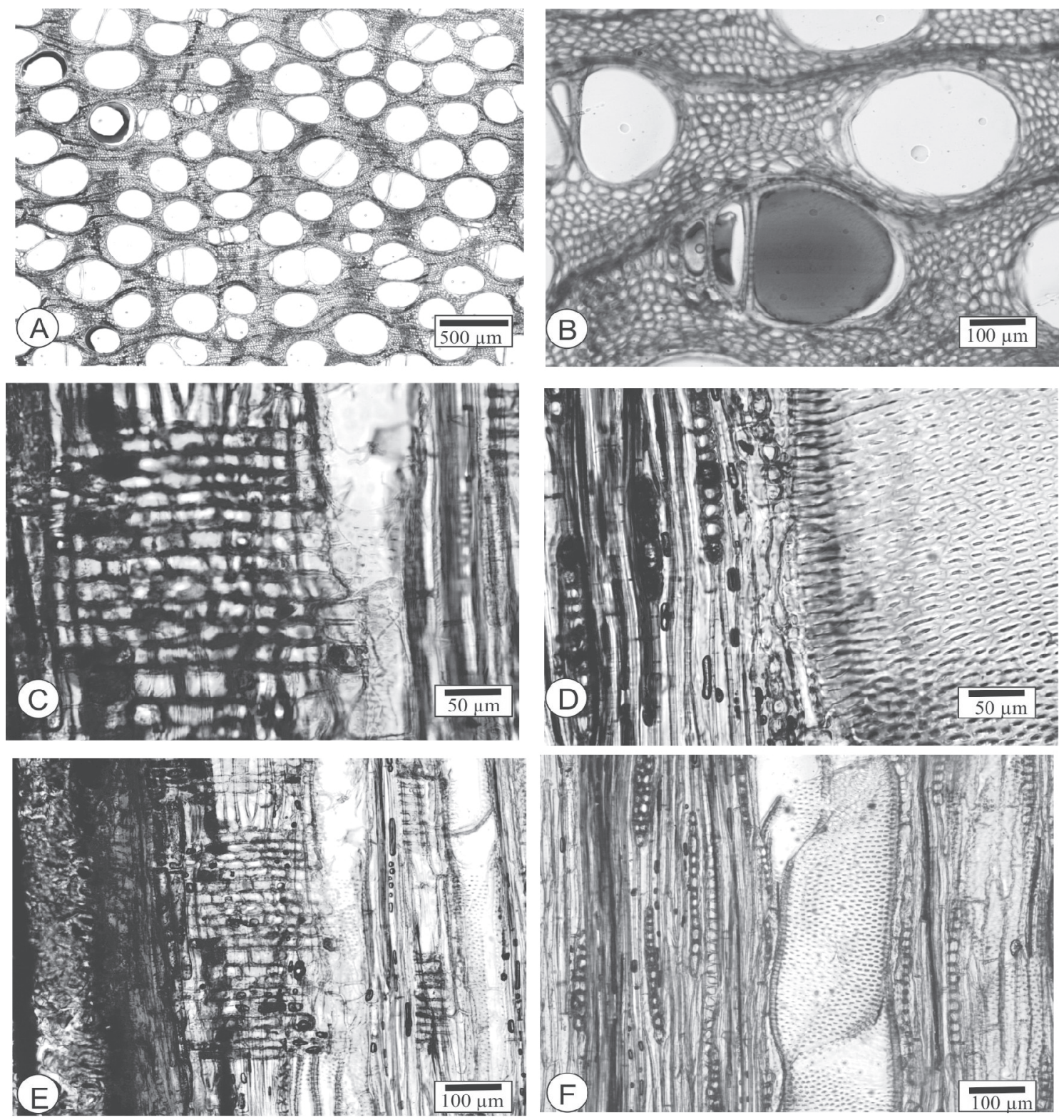

FIGURA 1 - Fotomicrografias do lenho de Senegalia martiusiana. A - Porosidade semi-difusa, poros solitários e em múltiplos radiais, limite de anel de crescimento e parênquima paratraqueal escasso (seção transversal). B - Mesmo plano anatômico, com maior aumento. C,E - Raio, inteiramente de células procumbentes, linhas vasculares e parênquima axial seriado, com cristais (seção radial). D, F-Raios finos e pontoações intervasculares ornamentadas (seção tangencial). 
A homogeneidade dos raios, observada no material em estudo, mostra-se valiosa, juntamente com a ausência de estratificação e o pequeno diâmetro das células radiais (em seção tangencial), para o posicionamento do material em estudo na subfamília Mimosoideae, de acordo com Baretta-Kuipers (1980, 1981).

A dimorfia de vasos, observada na espécie em estudo, é caráter de ampla ocorrência em lianas (Carlquist, 1975), devido ao valor ecofisiológico representado pela conjugação de vasos de pequeno e grande diâmetro.

\section{REFERÊNCIAS BIBLIOGRÁFICAS}

BARETTA-KUIPERS, T. The wood structure of leguminous tribes: their classification by ray and parenchyma features. Forest Products Abstract, v. 3, n. 8, p. 1-784, 1980.

BARETTA-KUIPERS, T. Wood anatomy of Leguminosae: its relevance to Taxonomy. In: POLHILL, R.M. \& RAVEN, P.H. Advances in Legume Systematics. 1981. p. 677-715.

BURGER, M.L.; RICHTER, H.G. Anatomia da madeira. São Paulo: Ed. Nobel,1991. 154 p.

BURKART, A. Leguminosas Mimosoideas. In: REITZ, R. Flora Ilustrada Catarinense. Itajaí: Herbário Barbosa Rodrigues, 1979. 299 p.

CARLQUIST, S. Ecological strategies in xylem evolution. Berkeley: University of California Press, $1975.259 \mathrm{p}$.

COZZO, D. Anatomía del leño secundario de las Leguminosas Mimosoideas y Caesalpinioideas argentinas silvestres y cultivadas. Rev. Inst. Nac. Invest. Ci. Nat. Ci Bot., Buenos Aires, v. 2, n. 2 , p. 63-290, 1951.

DUJARDIN, E.P. Eine neue Holz-Zellulosenfaerbung. Mikrokosmos, n. 53, p. 94, 1964.

FREUND, H. Handbuch der Mikroskopie in der Technik. Frankfurt: Umsham Verlag, 1970.

MARCHIORI, J.N.C. Estudo anatômico do xilema secundário e da casca de algumas espécies dos gêneros Acacia e Mimosa, nativas no estado do Rio Grande do Sul. Curitiba: Universidade Federal do Paraná, 1980a 185 f. Dissertação (Mestrado em Engenharia Florestal - UFPR).

MARCHIORI, J.N.C. Comprovação da viabilidade de utilização da seção longitudinal tangencial para a determinação histométrica dos elementos axiais do xilema secundário. In: CONGRESSO FLORESTAL ESTADUAL, IV. Nova Prata: Anais ..., 1980b. p. 180-184.

MARCHIORI, J.N.C. Estudo anatômico do xilema secundário e da casca de Acacia recurva Benth. (Leguminosae Mimosoideae). Ciência e Natura, Santa Maria, n. 4, p. 95-105, 1982.

MARCHIORI, J.N.C. Anatomia das madeiras do gêenero Acacia, nativas e cultivadas no estado do Rio Grande do Sul. Curitiba: Universidade Federal do Paraná, 1990. 226 f. Tese (Doutorado em Engenharia Florestal - UFPR).

MARCHIORI, J.N.C. Anatomia da madeira de Acacia nitidifolia Speg. (Leguminosae Mimosoideae). Ciência Florestal, Santa Maria, v.1, n. 1, p. 46-63, 1991.

MARCHIORI, J.N.C. Anatomia da madeira e casca de Acacia tucumanensis Gris. Ciência e Natura, Santa Maria, n. 16, p. 85-104, 1994.

MARCHIORI, J.N.C. Anatomia da madeira e casca de Acacia velutina DC. Ciência e Natura, Santa Maria, n. 17, p. 99-114, 1995.

MARCHIORI, J.N.C. Anatomia da madeira de Acacia bonariensis Gill. ex Hook \& Arn. Ciência Rural, Santa Maria, v. 26, n. 2, p. 209-216, 1996.

MARCHIORI, J.N.C.; SANTOS, S.R. dos. A segregação do gênero Acacia (Tourn.) Mill., sob o ponto da anatomia da madeira de espécies nativas e cultivadas no Rio Grande do Sul. Balduinia, Santa Maria, n. 30, p. 25-36, 2011.

METCALFE, C.R.; CHALK, L. Anatomy of the Dicotyledons. Oxford: Clarendon Press, 1949. $1500 \mathrm{p}$.

ORCHARD, A.E.; MASLIN, B.R. Proposal to conserve the name Acacia (Leguminosae: Mimosoideae) with a conserved type. Taxon, v. 52, p. 362-363, 2003.

PEREIRA, A.C. da S.; SIEGLOCH, A.M.; MARCHIORI, J.N.C. Anatomia do lenho de Senegalia visco (Lorentz ex Griseb.) Seigler \& Ebinger (Fabaceae). Balduinia, Santa Maria, n. 47, p. 19-23, 2015.

RICO-ARCE, M. de L. American species of Acacia. México: Comisión Nacional para el Conocimiento y Uso de la Biodiversidad (CONABIO), 2007. 207 p.

WHEELER, E.A.; BAAS, P.; GASSON, P.E. IAWA list of microscopic features for hardwood identification. IAWA Bulletin, v. 10, n. 3, 1989, p. 218-359. 